\title{
Erratum to: Characterization of Carbon Nanotube-Based Composites Under Consideration of Defects
}

\author{
M. Rahmandoust and M.R. Ayatollahi
}

Erratum to:

M. Rahmandoust and M.R. Ayatollahi, Characterization

of Carbon Nanotube-Based Composites Under Consideration

of Defects, Advanced Structured Materials 39,

DOI 10.1007/978-3-319-00251-4

\footnotetext{
The original online version for these chapters can be found at

DOI 10.1007/978-3-319-00251-4,

DOI 10.1007/978-3-319-00251-4_4,

DOI 10.1007/978-3-319-00251-4_5

M. Rahmandoust $(\triangle)$

Griffith School of Engineering, Griffith University (Gold Coast Campus),

Southport, Queensland, Australia

e-mail: moones.r@gmail.com

M. Rahmandoust

Protein Research Center, Shahid Beheshti University, G.C., 1983969411 Tehran, Iran

M.R. Ayatollahi

Fatigue and Fracture Research Laboratory, Center of Excellence in Experimental Solid Mechanics and Dynamics, School of Mechanical Engineering, Iran University of Science and Technology, Tehran, Iran

e-mail: m.ayat@iust.ac.ir
} 


\section{Preface:}

The last paragraph of the preface has been modified as below.

Finally, we appreciate the moment to express our sincere gratitude to Professor Dr.-Ing. Andreas Öchsner, editor-in-chief of the Springer book series on "Advanced Structured Materials" for his helpful guidance. We would like to thank Dr. Shahin Shadlou, Dr. Mohsen Khalily, Mr. Iman Eslami Afrouz, Mr. Mehdi Mavalizadeh, Mr. Morteza Farsadi, Mr. Ali Ghavamian and Mr. Reza Barbaz for their valuable assistance. Dr. Mostafa Rahmandoust, Mrs. Azar Rezaie and Dr. Hamidreza Kazempour should also be appreciated here for their kind support. In conclusion, we are grateful to many scientists worldwide, for their novel contributions to the topic, and for devoting their lives to keep the flame of knowledge and science burning brightly and beautifully through human history. We also thank Springer publisher for recognizing the necessity of the topic and the importance of characterization of defects in nanostructured materials. 


\section{Chapter 4: Revised Figures}

The legends for the figures 4.9, 4.11, 4.16, 4.24 were incomplete in chapter 4 . The missed out legends have been completed and updated in the original chapter.

Fig. 4.9 Typical forcedisplacement curves obtained for pure epoxy and for nanocomposites under mode I loading conditions (Ayatollahi et al. 2011f)
Fig. 4.11 Mixed mode I/II fracture toughness data obtained for pure epoxy and for nanocomposites (Ayatollahi et al. 2011f)
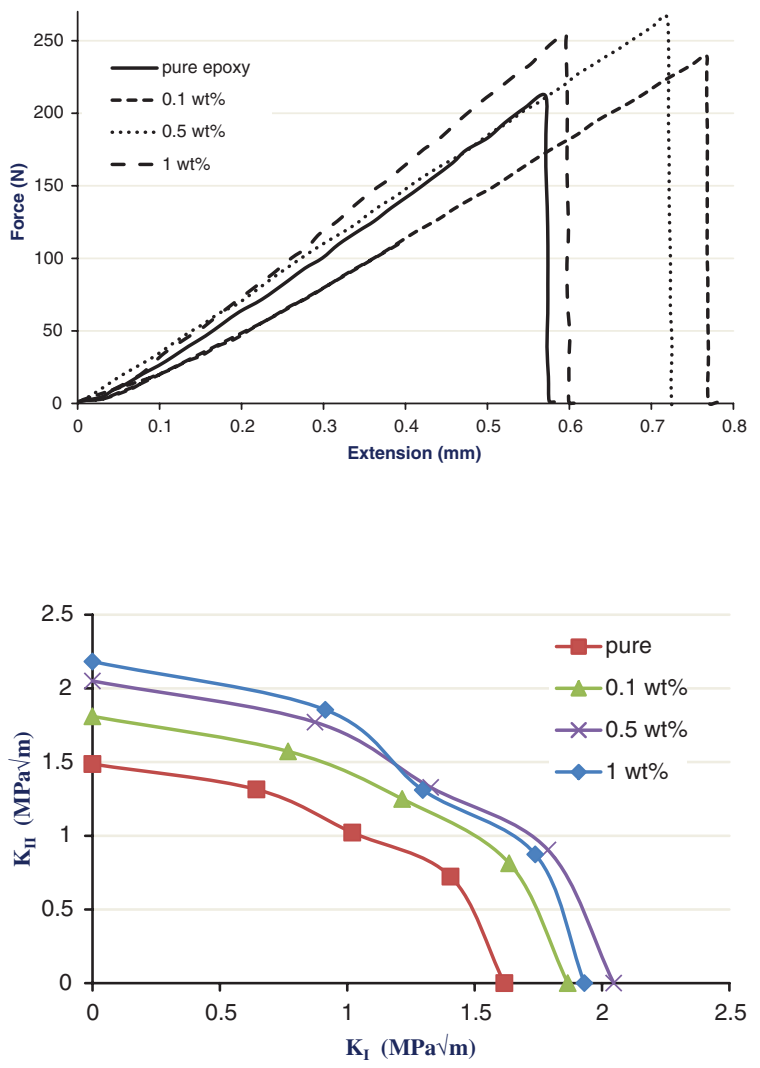
Fig. 4.16 Effects of MWCNT aspect ratio on mixed mode I/II fracture toughness data obtained for pure epoxy and for nanocomposites (Ayatollahi et al. 2011g)

Fig. 4.24 Apparent and ploughing coefficients of friction in terms of MWCNT percent content (Ayatollahi et al. 2012a)
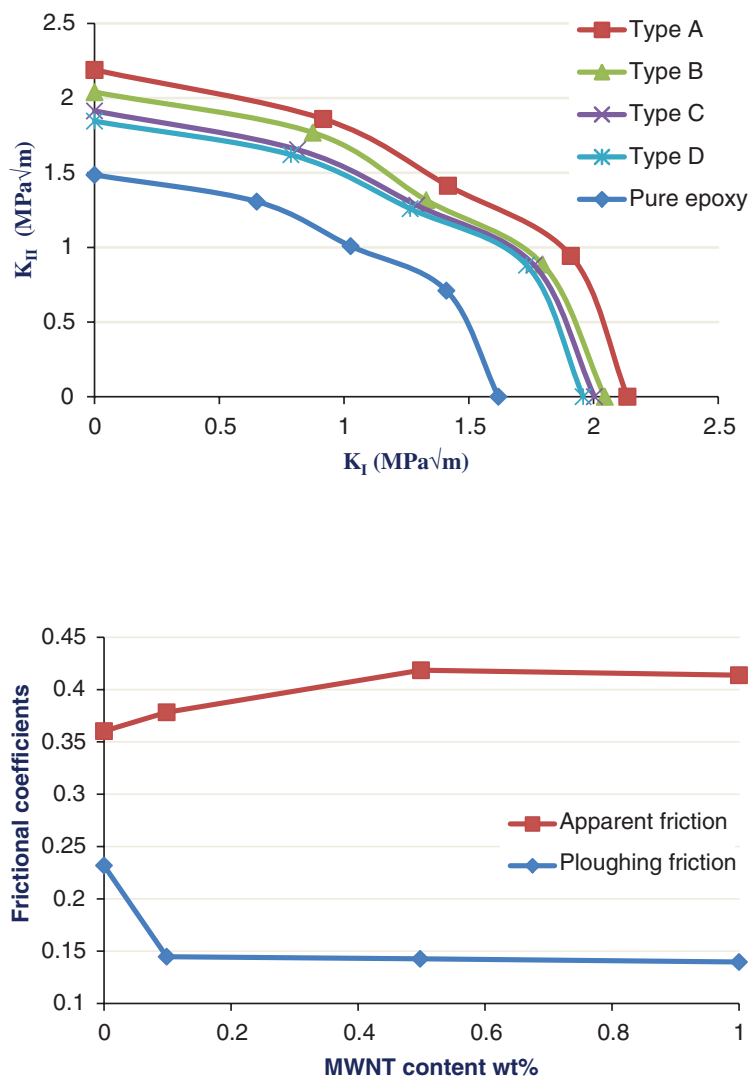


\section{Chapter 5: Revised Figure}

The legends for the figure 5.10 were incomplete in chapter 5. The missed out legends have been completed and updated in the original chapter.

Fig. 5.10 Experimental results obtained for the tensile behavior of various UD-laminates tested in the fiber direction. a The tensile modulus, $\mathbf{b}$ failure strength, c stress versus strain curves (Godara et al. 2009)
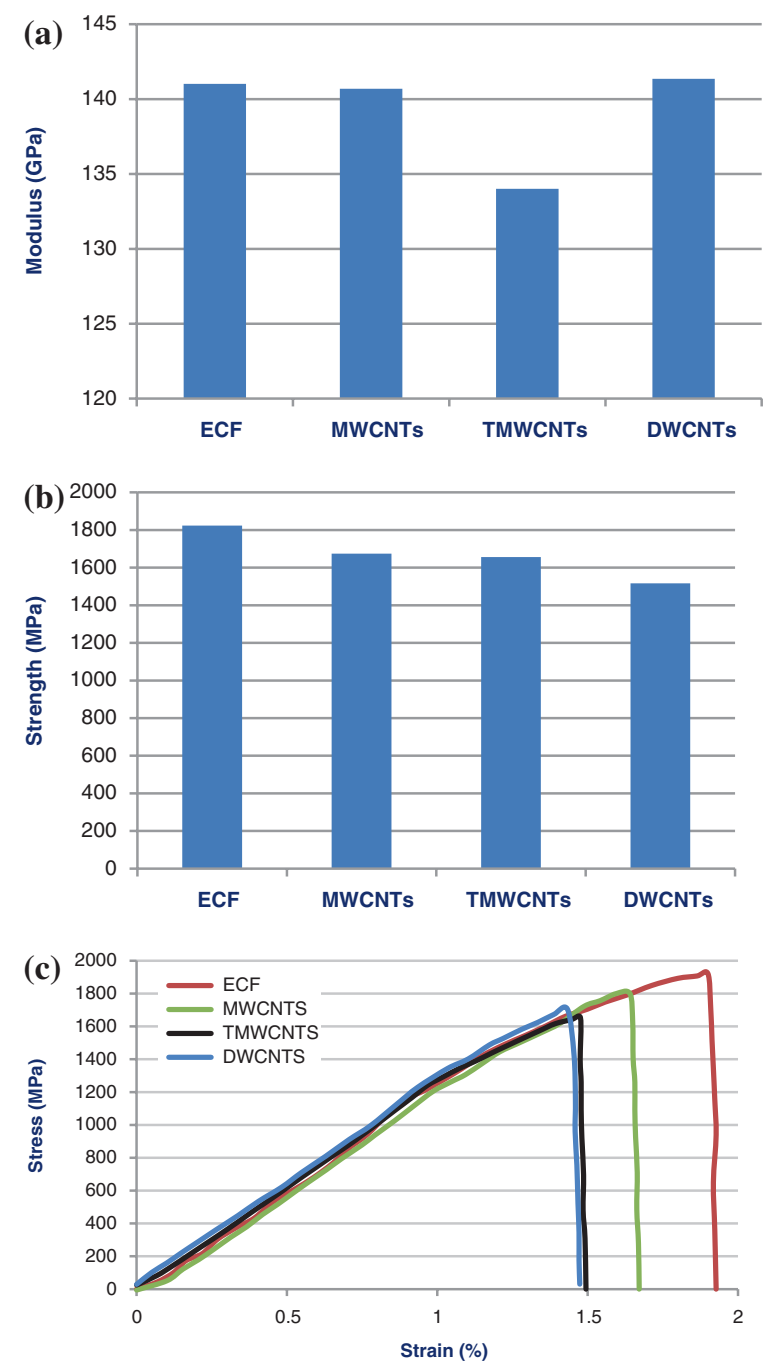